\title{
PAMPs and DAMPs in Allergy Exacerbation Models
}

\author{
Monique A.M. Willart, Philippe Poulliot, Bart N. Lambrecht, \\ and Mirjam Kool
}

\begin{abstract}
Sensitization of mice to real-life allergens or harmless antigen with the use of adjuvants will lead to the induction of DAMPs in the immune system. We have shown that the Th2-inducing adjuvant aluminum hydroxide or exposure of the airways to house dust mite leads to the release of DAMPs: uric acid, ATP, and IL-1. Exposure to DAMPs or PAMPs present in allergens or added to harmless allergens, such as the experimental allergen ovalbumin, induces several immune responses, including cellular influx and activation. Cellular influx can be analyzed by flow cytometry. Likewise, cellular activation can be assessed by measuring increased expression and release of chemokines and cytokines. These inflammatory mediators can be analyzed by ELISA or confocal microscopy. Here, we describe the protocols for these assessments and a protocol that takes advantage of bone marrow chimeric mice to further elucidate mechanism.
\end{abstract}

Key words Damage-associated molecular pattern, Pathogen-associated molecular pattern, Lung, Dendritic cell, Lung epithelium, Allergy, Asthma, Adjuvant

\section{Introduction}

In addition to the necessary $\mathrm{O}_{2} / \mathrm{CO}_{2}$, one breath contains many allergens and pollutions, like diesel and ozone. Individuals that are susceptible to these agents mount Th2 responses to the respective allergens. Common allergens include house dust mite antigen, various molds, and many types of pollen [1]. Allergic inflammation is characterized by an influx of eosinophils, goblet cell metaplasia, Th2 $\mathrm{T}$ cell responses, increased serum IgE levels, and, in the case of asthma, increased airway hyper-responsiveness. The development of Th2 responses is dependent on the innate arm of the immune system, which includes the release of both cytokines and chemokines by stromal cells and hematopoietic cells. These proinflammatory mediators can also be released by recruited cells, like neutrophils, monocytes, and dendritic cells (DCs). DCs are at the gateway between innate and adaptive immunity. DCs can phagocytose antigens and process them for presentation to antigen-specific $\mathrm{T}$ cells, which initiates a proper 
immune response $[1,2]$. However, in the airway, the interaction between DCs and lung epithelial cells is crucial [3]. Lung epithelial cells release several chemokines and cytokines shortly after exposure to allergens or pollutions that recruit and mature DCs to induce a immune responses [4]. Allergens can be accompanied by pathogenassociated molecular patterns (PAMPs) and damage-associated molecular patterns (DAMPs) can be induced and produced by host cells. PAMPs and DAMPs can both act as adjuvants to further strengthen the immune response. DCs, macrophages, and epithelial cells in the lung can sense PAMPs and DAMPs by the use of several pattern recognition receptors (PRRs) on their surface, such as Tolllike receptors (TLRs), Nod-like receptors (NLRs), and purinergic receptors (P2X- and P2Y-receptors).

As an example of PAMPs, lipopolysaccharide (LPS) is a commonly used stimulus in experiments to induce maturation on DCs via TLR4 signaling. It even has been shown to induce Th2 sensitization to a harmless antigen, whereof the amount of LPS is able to shift the balance to Thl or Th2 $[5,6]$. Another well-known DAMP, adenosine triphosphate (ATP), is able to signal on DCs via the P2X7 receptor $[7,8]$. TLR4 signaling on DCs will lead to NF- $\kappa \mathrm{B}$ activation, which subsequently leads to the secretion of inflammatory cytokines, such as pro-IL-1 $\beta$ and pro-IL-18. A second signal, like ATP binding, activates potassium efflux via the P2X7R and, when combined with pannexin- 1 , leads to the activation of the NLRP3 inflammasome. NLRP3 inflammasome activation results in the activation of caspase- 1 . This enzyme cleaves pro-IL-1 $\beta$ and pro-IL-18 into their bioactive forms and these cytokines will be secreted [9].

Aluminum-containing adjuvants, which are used in many vaccines, stimulate the release of uric acid (UA). UA crystals are another proinflammatory DAMP that can directly activate the NLRP3 inflammasome [10, 11]. However, recently we have shown that UA does not need the NLRP3 inflammasome or IL-1 axis to induce Th2 immunity. Instead, UA activation of the immune system for Th2 induction is dependent on spleen tyrosine kinase (Syk) and PI3-kinase delta signaling $[12,13]$.

Sensitization of mice to real-life allergens or harmless antigens with the use of adjuvants will lead to the induction of DAMPs by the immune system. We have shown that the Th2-inducing adjuvant aluminum hydroxide or exposure of the airways to house dust mite leads to the release of the DAMPs: uric acid, ATP, and IL- 1 . This release is measured in either the peritoneal lavage (PL), in the case of an intraperitoneal antigen injection combined with adjuvant, or the broncho-alveolar lavage (BAL), in the case of airway sensitization. Here, we describe a set of protocols to induce and analyze the release of different DAMPs and PAMPs with particular emphasis on ATP, IL-1, and UA. 
Table 1

\section{Mouse strains available to study the role of TLRs and signaling pathways}

\begin{tabular}{ll}
\hline Knockout strain & Reference \\
\hline IRAK1-/- & Thomas J.A., et al.; J Immunol 1999 \\
\hline IRAK2-/- & Wang Y., et al; J Biol Chem 2009 \\
\hline IRAK4-/- & Suzuki N., et al; Nature 2002 \\
\hline IRF3-/- & T. Taniguichi (Tokyo, Japan) \\
\hline IRF7-/- & Riken BioResource Center (Tsukuba, Japan) \\
\hline MyD88-/- & Adachi O., et al.; Immunity 1998 \\
\hline TBK-/- & Sato S., et al.; J Immunol 2003 \\
\hline TLR1-/- & Alexopoulou L., et al.; Nat Med 2002 \\
\hline TLR2-/- & Wooten R.M., et al; J Immunol 2002 \\
\hline TLR3-/- & Alexopoulou L., et al.; Nature 2001 \\
\hline TLR4-/- & Poltorak A., et al.; Science 1998 \\
\hline TLR5-/- & Vijay-Kumar M., et al.; J Clin Invest 2007 \\
\hline TLR6-/- & Sugawara I., et al.; Microbiol Immunol 2003 \\
\hline TLR7-/- & Hemmi H., et al.; Nat Imm 2002 \\
\hline TLR8-/- & Demaria O., et al.; J Clin Invest 2010 \\
\hline TLR9-/- & Hemmi H., et al.; Nature 2000 \\
\hline TLR11-/- & Zhang D., et al.; Science 2004 \\
\hline TLR13-/- & Shi Z., et al.; J Biol Chem 2010 \\
\hline TRAF6-/- & Lomaga M.A., et al.; Genes Dev 1999 \\
\hline TRIF-/- & Hoebe K., et al.; Nature 2003 \\
\hline
\end{tabular}

The TLRs play an important role in the recognition of PAMPs. The TLR family in mice consists of 12 family members. TLRl, TLR2, TLR4, TLR5, and TLR6 are localized on the cell surface mainly recognizing microbial membrane components, such as LPS and flagellin, whereas TLR3, TLR7, TLR8, and TLR9 are expressed within intracellular vesicles and recognize dsRNA, ssRNA, CPG, and DNA [14]. Downstream of TLR signaling, adaptor molecules like MyD88, BTK, IRAK4, IRAKI, and IRAK2 eventually lead to TRAF6 ubiquitination and NF- $\mathrm{KB}$ activation. Another activation pathway via TRAM/TRIF forms complexes with TBKI and subsequently activates IRF3. Activation of IRF3 leads to type I IFN production $[14,15]$.

To study the role of these TLRs and their signaling molecules in allergic asthma models, various knockout strains are available as summarized in Table .l. 


\section{Table 2 \\ Mouse strains available to study the role of DAMPs and signaling pathways}

\begin{tabular}{|c|c|}
\hline Knockout strain & Reference \\
\hline ASC- $-/-$ & Mariathasan S., et al.; Nature 2004 \\
\hline Caspasel-/- & Kayagaki N.; Nature 2011 \\
\hline IL-1RI-/- & Labow M., et al.; J Immunol 1997 \\
\hline Ipaf-/- & Franchi L., et al.; Nat Imm 2006 \\
\hline NLRP3-/- & Kanneganti T.D., et al.; Nature 2006 \\
\hline NLRP6- /- & Chen G.Y., et al.; J Immunol 2011 \\
\hline $\mathrm{P} 2 \mathrm{X} 1 \mathrm{R}-/-$ & Mulryan K., et al.; Nature 2000 \\
\hline $\mathrm{P} 2 \mathrm{X} 2 \mathrm{R}-/-$ & Cockayne D.A., et al.; J Physiol 2005 \\
\hline P2X3R-/- & $\begin{array}{l}\text { Cockayne D.A., et al.; Nature } 2000 \\
\text { and Zhong Y., et al.; Eur J Neurosci } 2001\end{array}$ \\
\hline $\mathrm{P} 2 \mathrm{X} 7 \mathrm{R}-/-$ & Pelegrin P. and Suprenant A.; EMBO 2006 \\
\hline Pannexin-1-/- & Qu Y., et al.; J Immunol 2011 \\
\hline RAGE-/- & Lexicon Genetics Incorporated, Woodlands, TX, USA \\
\hline Uricase- $/-$ & Wu X., et al.; Proc Natl Acad Sci U S A 1994 \\
\hline Uricase- $\mathrm{Tg}$ & Kono H., et al.; J Clin Invest 2010 \\
\hline
\end{tabular}

Multiple mouse strains are also available to study the role of DAMPs in allergic asthma (Table 2). Some well-known DAMPs that have been shown to have adjuvant activity are IL-l $\alpha$, highmobility-group protein 1 (HMGB1) and ATP [16-18]. For these, the danger signals are also defined receptors like IL-1RI, RAGE, and the P2X receptors. However, the receptors for many DAMPs are not known. For example, uric acid is a potent inducer of Th2 immunity $[12,19]$; however, the receptor that senses uric acid has not been identified. Therefore, to study the role of uric acid, uricase-deficient mouse strains can be used.

Some DAMPs activate the intracellular NALP/IPAFinflammasomes [20]. For example, NLRP3 can be activated by uric acid crystals, alum adjuvant, and potassium efflux via pannexin-1 hemichannels. Inflammasome activation leads to recruitment of the adaptor molecule ASC and the subsequent activation of caspase- 1 , which is needed to cleave an assortment of procytokines into their bioactive forms [21]. Knockout mouse lines have proven to be vital for these studies.

Here, we describe methods used to evaluate DAMPs, with special emphasis on uric acid, during the induction of allergic airway inflammation. We also describe methods to use DAMPs and PAMPs 
as adjuvants and protocols to evaluate cytokine and chemokine production. Finally, we detail the process of generating bone marrow chimera mice and steps to evaluate dendritic cell migration.

\section{Materials}

\subsection{Peritoneal Lavage and Broncho- Alveolar Lavage}

2.2 ATP

Measurement

in $B A L$ and $P L$

2.3 Uric Acid Measurement in $B A L$ and $P L$

2.4 Uric Acid Detection on Cryosections
1. C57BL/6 or BALB/c mice can be obtained from certified providers such as Harlan or Jackson Labs (see Note 1).

2. Pipet for $50 \mu \mathrm{l}$ administration (required for intratracheal/ intranasal administration).

3. Inhalation anesthesia administration station (preferentially for isoflurane).

4. Allergen-House Dust Mite Antigen (Greer Laboratories).

5. Allergen-Ovalbumin (OVA).

6. Adjuvant (Imject alum, Pierce).

7. Trachea catheter for BAL $(23 \mathrm{G}$ needle with a piece of PE50 tubing).

8. Suture: 3-0 silk thread.

9. $23 \mathrm{G}$ needle with a $2.5 \mathrm{ml}$ syringe for PL.

10. $0.5 \mathrm{mM}$ EDTA/PBS.

11. Ice.

1. ATPlite ${ }^{\mathrm{TM}}$ Luminescence Assay System (Perkin Elmer).

2. Plate reader to detect luminescence.

1. Amplex ${ }^{\circledast}$ Red Uric Acid/Uricase Assay Kit (Invitrogen).

2. Plate reader to detect luminescence.

1. Tissue-Tek (Sakura)/PBS solution, ratio 1:1 (see Note 2).

2. Liquid nitrogen.

3. Cryostat.

4. Adhesive microscope slides and coverslips.

5. $4 \%$ Paraformaldehyde (PFA) in PBS.

6. Block buffer: $1 \%$ Blocking reagent (Roche) in PBS.

7. Anti-uric acid antibody (Abcam).

8. Goat-anti-rabbit Ig-Cy3 (Jackson Immunoresearch).

9. 4',6-Diamidino-2-Phenylindole dihydrochloride (DAPI).

10. Polyvinyl alcohol mounting medium with $\mathrm{DABCO}^{\circledR}$, anti-fading. 


\subsection{Lung Homogenates}

2.6 ELISA
1. C57BL/6 or BALB/c mice can be obtained from certified providers such as Harlan or Jackson Labs.

2. Allergens, DAMPs, and PAMPs of interest.

3. Trachea catheter: $23 \mathrm{G}$ needle with piece of PE50 tubing.

4. Suture: 3-0 silk thread.

5. $0.5 \mathrm{mM}$ EDTA/PBS.

6. Liquid nitrogen.

7. Tissue homogenizer: IKA T10 rotor-stator homogenizer, with a 5 or a $7 \mathrm{~mm}$ generator.

8. $2 \mathrm{ml}$ safe-lock tubes.

9. Cold lysis buffer: $20 \mathrm{mM}$ Tris- $\mathrm{HCl}(\mathrm{pH} 8.0$ ), $0.14 \mathrm{M} \mathrm{NaCl}$, $10 \%$ glycerol (v/v), 1 mM PMSF, $1 \mathrm{mM}$ sodium orthovanadate $\left(\mathrm{Na}_{3} \mathrm{VO}_{4}\right), 1 \mu \mathrm{M} \mathrm{NaF}, 40 \mathrm{mg} / \mathrm{ml}$ aprotinin, and $20 \mathrm{mg} /$ $\mathrm{ml}$ of leupeptin. Protease inhibitors should be prepared fresh on the day of use (see Notes 3 and $\mathbf{4}$ ).

10. Igepal (US Biological).

11. NanoOrange protein quantitation assay (Invitrogen).

12. Plate reader to detect fluorescence.

13. Eppendorf centrifuge.

14. Mini-labroller.

1. Half area plate Microlon 600 (Greiner) or 96 well plate Maxisorp (NUNC). In the Greiner plate, $50 \mu \mathrm{l}$ samples are required per well. If NUNC plates are used, $100 \mu \mathrm{l}$ samples are required per well.

2. Coating buffer: The choice of coating buffer depends on the antibody used. Typical coating buffers are either $0.1 \mathrm{M}$ sodium carbonate, $\mathrm{pH} 9.5$ or $0.2 \mathrm{M}$ sodium phosphate, $\mathrm{pH} 6.5$.

3. Wash buffer: $0.05 \%$ Tween-20 in $1 \times$ PBS.

4. $10 \%$ Fetal calf serum (FCS) in $1 \times$ PBS.

5. Purified antibody (coating), biotinylated antibody (detection), and streptavidin-HRP for the specific protein being assayed.

6. TMB substrate solution.

7. Stop solution: $2.5 \mathrm{~N} \mathrm{H}_{2} \mathrm{SO}_{4}$.

8. Plate reader.

1. Cryostat.

2. Tissue-Tek (Sakura)/PBS solution, ratio 1:1.

3. Liquid nitrogen.

4. Adhesive microscope slides and coverslips.

5. PBS, pH 7.4-7.8. 
6. $4 \%$ PFA at $4{ }^{\circ} \mathrm{C}$ (1:10 dilution of $37 \%$ PFA in PBS).

7. $1 \%$ Blocking reagent (Roche Applied Science) in PBS.

8. Normal donkey serum.

9. Normal goat serum and normal mouse serum.

10. Rat anti-MCP-1 (Abcam).

11. Donkey anti-rat conjugated with Cy3 (Jackson Immunoresearch).

12. $1 \mathrm{mg} / \mathrm{ml}$ of DAPI, stock.

13. Polyvinyl alcohol mounting medium with DABCO.

14. Confocal microscope.

2.8 Bone Marrow Chimeric Mice

2.9 Innate

Cellular Influx and DC Migration
1. Bone marrow donor mice of WT and KO origin.

2. Bone marrow acceptor mice of WT and KO origin, which will be irradiated.

3. Irradiation device (X-Rad 320, RPS).

4. Enrofloxacin (antibiotic).

5. Heating lamp.

6. Inverted microscope.

7. Sterilized pestle and mortar.

8. Red blood cell (RBC)-lysis buffer: $0.15 \mathrm{M} \mathrm{NH}_{4} \mathrm{Cl}, 1 \mathrm{mM}$ $\mathrm{KHCO}_{3}, 0.1 \mathrm{mM} \mathrm{Na}_{2}$ EDTA. Filter-sterilize before use.

9. $1 \times$ HBSS and D-PBS.

10. $100 \mu \mathrm{m}$ cell strainer.

11. $0.4 \%$ Trypan blue solution, diluted 1:10 in $1 \times$ PBS.

12. Tubes, pipets, pipet tips, syringes, needles.

1. FACS buffer: $1 \times$ PBS, $0.25 \%$ BSA, 0.5 mM EDTA, $0.05 \%$ $\mathrm{NaN}_{3}$.

2. Low-binding flexiplates.

3. OVA-Alexa Fluor 647.

4. DAPI.

5. Fixable live/dead Aqua.

6. FACS tubes.

7. $1 \times$ HBSS.

8. Multi-well plates and $15 \mathrm{ml}$ tubes.

9. Tweezer and curved iris scissor.

10. $35 \mathrm{~mm}$ petri dishes.

11. $100 \mu \mathrm{m}$ cell strainers.

12. Pasteur pipets. 
13. Digestion medium: Liberase ${ }^{\mathrm{TM}}$ (Roche) and DNase I in RPMI generated as directed by manufacturer.

14. 14. RBC-lysis buffer: $0.15 \mathrm{M} \mathrm{NH}_{4} \mathrm{Cl}, 1 \mathrm{mM} \mathrm{KHCO} 3,0.1 \mathrm{mM}$ $\mathrm{Na}_{2}$ EDTA. Filter-sterilize before use.

15. Water bath at $37^{\circ} \mathrm{C}$.

16. 96-Well filter plate or cell strainer-capped tubes.

17. Flow cytometer (equipped with a 405, 488, and $633 \mathrm{~nm}$ laser).

\section{Methods}

\subsection{Intratracheal Injection of Allergens}

1. Anesthetize mice according to local guidelines.

2. Suspend the anesthetized mouse by the upper front teeth. This puts the mouse in a position where the head is vertical, and the body is suspended on the apparatus. It is an optimal position for the trachea to be vertical, which allows the liquid to effectively reach the airways.

3. Pull the tongue out of the mouth of the animal using blunt forceps. Hold the tongue on one side of the mouth while maintaining it in an extended position. This is extremely important, as it ensures that the mouse is not able to swallow and allows the allergen to reach the trachea.

4. Inject liquid just above the vocal cords in the mouth of the mouse. The mouse will gradually inhale the liquid.

5. Once the liquid is inhaled and the breathing rate has returned to normal, release the tongue.

6. If an injectable anesthesia is utilized, place the mouse on a heating mat to recover.

7. At the desired time point, euthanize mice and expose the trachea.

8. Insert the suture thread between the esophagus and the trachea.

9. With scissors, make a small incision into the trachea between the cartilage rings. The incision should be large enough to insert the catheter. Care should be taken to avoid cutting the trachea completely.

10. Insert the catheter into the trachea towards the lungs. Secure the catheter in place with the ligature.

11. Using EDTA/PBS at RT, wash the lung three times through the catheter with the same $1 \mathrm{ml}$. Place the retrieved BAL-fluid in a 15-ml tube. The whole $1 \mathrm{ml}$ must be injected and slowly retrieved ( see Note 5).

12. Keep the BAL fluid on ice during the procedure.

13. Centrifuge BAL samples at $400 \times g$ at $4{ }^{\circ} \mathrm{C}$ for $7 \mathrm{~min}$ and transfer the supernatant into a new tube (see Note 6). It is very important 


\subsection{Intraperitoneal Injection of Allergens Combined with Adjuvant}

\subsection{Uric Acid Measurement on Cryosections}

that samples be kept cold. Samples should be used immediately for the measurement of ATP. For uric acid and IL-1 measurements, the supernatant can be stored at $-20{ }^{\circ} \mathrm{C}$ until further analysis.

14. The measurement of ATP and uric acid in the supernatant is done according to the manufacturer's protocol.

1. Inject $10 \mu \mathrm{g}$ of allergen, such as OVA, combined with $1 \mathrm{mg}$ of alum in $500 \mu \mathrm{l}$ of saline intraperitoneally (i.p.).

2. Sacrifice the mouse after $2 \mathrm{~h}$ by $\mathrm{CO}_{2}$ inhalation (see Note 7 ).

3. Gently cut the skin of the abdomen. Incisions should begin as close as possible to the leg area and care should be taken to avoid cutting the muscles of the abdomen.

4. Cut from the lowest part of the abdomen to the thorax and gently remove the skin from the muscles.

5. Inject $3 \mathrm{ml}$ of warm EDTA/PBS i.p.

6. Gently massage/shake the mouse and recollect the EDTA/ PBS back into the syringe. Usually, $2-2.5 \mathrm{ml}$ is collected.

7. Store on ice immediately.

8. Centrifuge PL samples at $400 \times g$ at $4{ }^{\circ} \mathrm{C}$ for $7 \mathrm{~min}$ and transfer the supernatant into a new tube (see Note 6). It is very important that samples be kept cold. Samples should be used immediately for the measurement of ATP. For uric acid and IL-1 measurement, the supernatants can be stored at $-20{ }^{\circ} \mathrm{C}$ until further analysis.

9. The measurement of ATP and uric acid in the supernatant is done according to the manufacturer's protocol.

1. Inflate the mouse lung via the trachea with $1 \mathrm{ml}$ of TissueTek/PBS solution via the trachea-catheter used to collect the BAL.

2. Lungs should be snap frozen in liquid nitrogen and kept at $-80^{\circ} \mathrm{C}$ until further use.

3. Make $6-\mu \mathrm{m}$-thick cryosections.

4. Dry sections before storage at $-80^{\circ} \mathrm{C}$ or before staining.

5. Fix the slides in $4 \% \mathrm{PFA}$ for $10 \mathrm{~min}$ at room temperature (see Note 8).

6. Wash the slides two times with PBS for 5 min per wash.

7. Block the slides with $10 \%$ normal goat serum in block buffer for $10 \mathrm{~min}$.

8. Wash the slides two times with PBS for 5 min per wash.

9. Incubate the sections for $\mathrm{l} \mathrm{h}$ with anti-uric acid antibody (rabbit Ig) in block buffer (see Note 9). 


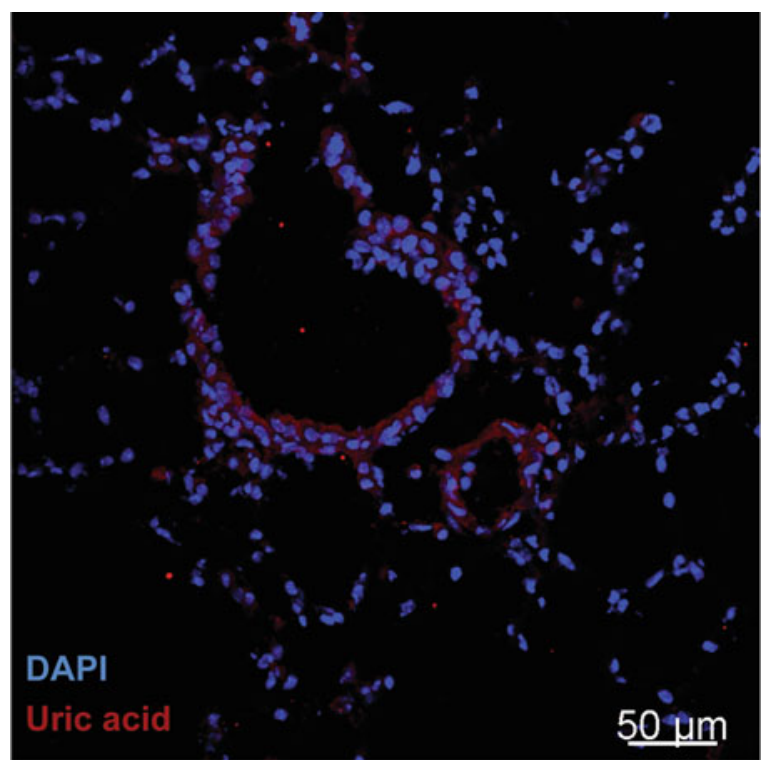

Fig. 1 Picture of a lung section stained for uric acid and DAPI. Bronchial epithelial and endothelial cells stain positive for uric acid

10. Wash the slides two times with PBS for 5 min per wash.

11. Incubate the sections for $30 \mathrm{~min}$ with goat anti-rabbit Ig-Cy3 in block buffer.

12. Wash the slides two times with PBS for 5 min per wash.

13. If other markers are to be evaluated, additional antibodies can be utilized to stain the sections.

14. Stain nuclei using DAPI ( $1 \mu \mathrm{g} / \mathrm{ml}$ in PBS) for $5 \mathrm{~min}$.

15. Wash the slides two times with PBS for $5 \mathrm{~min}$ per wash.

16. Wash the slides with $\mathrm{H}_{2} \mathrm{O}$ for 5 min.

17. Mount slides with polyvinylethanol.

18. Analyze slides with a confocal microscope (Fig. 1).

3.4 Preparation of Lung Homogenates
1. Inject the allergens intratracheally and perform BAL as described in Subheading 3.1.

2. To analyze lung cellular influx and cytokine/chemokine responses to allergens, DAMPs or PAMPs, harvest the BAL and lung tissue at several time points after exposure. Samples should be collected at time points between 2 and $48 \mathrm{~h}$.

3. BAL supernatant can be used for ELISA to determine the levels of cytokines and chemokines. The cells in the BAL can be analyzed for cellular influx by FACS-analysis (described in Subheading 3.9).

4. Open the chest of the mouse, dissect the left lobe of the lung, and collect it in the $2 \mathrm{ml}$ tube. Snap-freeze the lung lobe in 
liquid nitrogen and store at $-80{ }^{\circ} \mathrm{C}$ until homogenates are made. The right lobes can be dissected and maintained in HBSS on ice for the generation of cell suspensions for FACS-analysis.

5. Homogenize the lung. Add $400 \mu \mathrm{l}$ of cold lysis buffer to the frozen lung samples and immediately homogenize them using a rotor-stator homogenizer equipped with a 5 or a $7 \mathrm{~mm}$ generator for 1.5 or $2 \mathrm{ml}$ Eppendorf tubes. Tube sizes may extend up to $5 \mathrm{ml}$ tubes, depending on lab availability. The speed of the homogenizer should be adjusted to avoid foaming. Foaming could alter the quality of the proteins and reduce the practical volume recovered. The homogenization is complete when no macroscopic pieces of lung are visible in the solution. Place the samples on ice until all of the samples are homogenized.

6. Add $1 \% \mathrm{v} / \mathrm{v}$ Igepal to each sample, vortex for $5 \mathrm{~s}$, and place the sample back on ice (see Note 10).

7. Place all of the samples in a mini-labroller for $20 \mathrm{~min}$ at $4{ }^{\circ} \mathrm{C}$. Alternatively, samples can be left on ice for $45 \mathrm{~min}$ with vortexing occurring every $5 \mathrm{~min}$.

8. Centrifuge the samples at $16,000 \times g$ at $4{ }^{\circ} \mathrm{C}$ for $15 \mathrm{~min}$ and transfer the supernatant into a new tube. Collect $10 \mu \mathrm{l}$ of each sample for NanoOrange protein content measurements.

9. Store supernatant at $-80^{\circ} \mathrm{C}$ until ELISA is performed. Use the NanoOrange kit to measure and normalize the protein content.

\subsection{Cytokine Measurement by ELISA}

1. Coat the ELISA plates with purified antibody in an appropriate coating buffer overnight at $4{ }^{\circ} \mathrm{C}$. For half-area plates, use $50 \mathrm{\mu l}$ /well; otherwise double all volumes described below.

2. Wash the wells three times with $150 \mu \mathrm{l} /$ well of wash buffer and empty wells by blotting the plate on an absorbent towel.

3. Block the uncoated spots in wells with $150 \mu \mathrm{l}$ /well of $10 \%$ FCS $/ \mathrm{PBS}$ and incubate the plate for $\mathrm{l} h$ at room temperature.

4. Wash the wells once with $150 \mu \mathrm{l} /$ well of wash buffer and empty the wells by blotting the plate on an absorbent towel.

5. Add $50 \mu \mathrm{l} /$ well of samples, standards, and blank (in either duplicate or triplicate) and incubate the plate for $2-2.5 \mathrm{~h}$ at room temperature.

6. Wash the wells five times with $150 \mu \mathrm{l} /$ well of wash buffer and empty the wells by blotting the plate on an absorbent towel.

7. Add $50 \mu \mathrm{l} /$ well of detection antibody diluted in $10 \%$ FCS/ PBS. Incubate the plate for $\mathrm{l}-2 \mathrm{~h}$ at room temperature.

8. Wash the wells five times with $150 \mu \mathrm{l} /$ well of wash buffer and empty the wells by blotting the plate on an absorbent towel. 


\subsection{Chemokine Measurement by Confocal Microscopy}

9. Add $50 \mu \mathrm{l} /$ well of streptavidin diluted in $10 \%$ FCS/PBS. Incubate the plate for $30 \mathrm{~min}$ at room temperature.

10. Wash wells five times with $150 \mu \mathrm{l} /$ well of wash buffer and empty the wells by blotting the plate on an absorbent towel.

11. Add $50 \mu \mathrm{l} /$ well of TMB substrate solution into each well and incubate the plate for $10-30 \mathrm{~min}$ in the dark at room temperature.

12. Stop the reaction by adding $25 \mu \mathrm{l} /$ well of stop solution and measure the wavelength using a plate reader set at $405 \mathrm{~nm}$ and reference at $650 \mathrm{~nm}$.

1. Inflate the mouse lung via the tracheal catheter with $1 \mathrm{ml}$ of Tissue-Tek/PBS solution.

2. The lungs should be snap frozen in liquid nitrogen and stored at $-80{ }^{\circ} \mathrm{C}$ until further use.

3. Make $6-\mu \mathrm{m}$ cryosections using a cryostat and store these sections at $-80^{\circ} \mathrm{C}$. However, if the staining is to be performed on the same day, air-dry the sections for $1 \mathrm{~h}$ prior to staining.

4. Fix the slides for $10 \mathrm{~min}$ in $4 \% \mathrm{PFA}$ at $4{ }^{\circ} \mathrm{C}$.

5 . Incubate the sections with $10 \%$ normal donkey serum in $1 \%$ blocking reagent (see Note 8) for $10 \mathrm{~min}$ at room temperature.

6. Rinse slides with PBS for $2 \mathrm{~min}$.

7. Add anti-MCPl antibody diluted in $1 \%$ blocking reagent to each slide and incubate for $\mathrm{l}$ h at room temperature (see Note 9 ). The antibody dilutions should be optimized prior to use and can vary per lab.

8. Rinse slides with PBS for 2 min.

9. Add donkey anti-rat antibody diluted 1:50 in $1 \%$ blocking reagent and incubate for $30 \mathrm{~min}$ at room temperature in the dark.

10. Rinse slides with PBS for $2 \mathrm{~min}$.

11. Add DAPI diluted $1: 1,000$ in PBS and incubate for $5 \mathrm{~min}$.

12. Rinse slides with PBS for $2 \mathrm{~min}$ and $\mathrm{ddH}_{2} \mathrm{O}$ for $2 \mathrm{~min}$.

13. Mount slides with mounting medium and coverslip and leave them overnight at room temperature to allow the mounting medium to polymerize. Analyze the slides under a confocal microscope (Fig. 2).

1. 8-10-week-old mice (WT and KO) are sublethally irradiated with 8-10 Gy (X-Rad 320, RPS) (see Notes 11 and 12). The mice are subsequently placed back into their home cages for at least $4 \mathrm{~h}$.

\subsection{Bone Marrow Chimeric Mice}




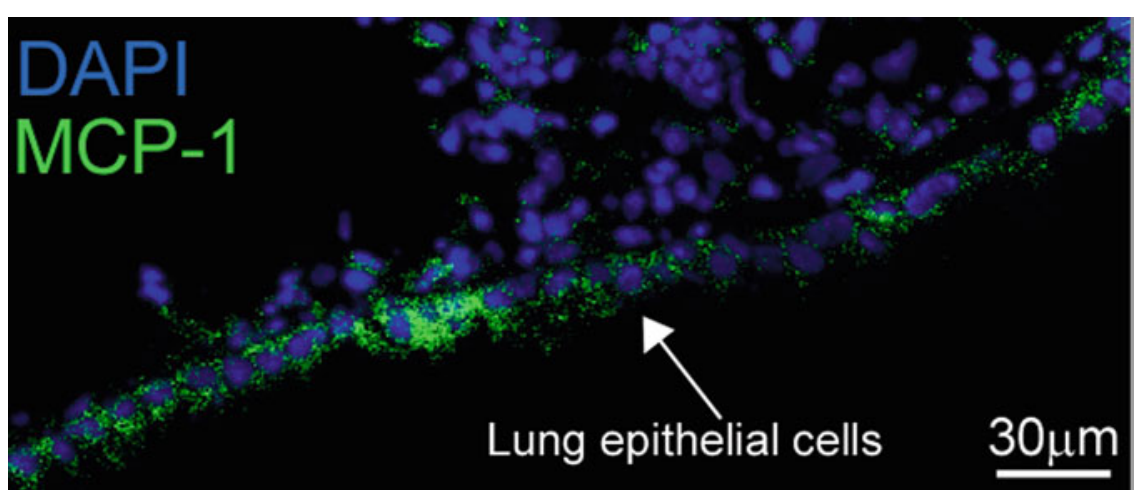

Fig. 2 Picture of a lung section after exposure to LPS and stained for MCP-1 and DAPI. Bronchial epithelial cells stain positive for MCP-1

2. Isolate femurs and tibias from bone marrow donor mice and collect the bones in cold HBSS.

3. Incubate bones for $2 \mathrm{~min}$ with $70 \%$ ethanol and wash twice with cold HBSS.

4. Transfer bones in a sterilized mortar and smash the bones in a small volume of HBSS with a pestle.

5. Rinse the pestle and the mortar with a larger volume of $1 \times$ HBSS and transfer the cell suspension through a $100 \mu \mathrm{m}$ cell strainer, placed in a $50 \mathrm{ml}$ tube.

6. Centrifuge the cells at $400 \times g$ for $7 \mathrm{~min}$ at $4{ }^{\circ} \mathrm{C}$.

7. Suspend the cell pellet in RBC lysis buffer ( $1 \mathrm{ml} / \#$ of mice).

8 . Incubate the cells for $4 \mathrm{~min}$ on ice and shake occasionally.

9. Add an excess amount of cold D-PBS to stop the lysis and centrifuge the cell suspension at $400 \times g$ for $7 \mathrm{~min}$ at $4{ }^{\circ} \mathrm{C}$.

10. Suspend the cell pellet in D-PBS.

11. Remove an aliquot of each sample and combine with Trypan blue solution in a 1:1 ratio. Count the live cells $/ \mathrm{ml}$ (dead cells stain blue) using a hemacytometer.

12. Centrifuge the remaining cells at $400 \times g$ for $7 \mathrm{~min}$ at $4{ }^{\circ} \mathrm{C}$ and suspend the pellet in D-PBS. The final concentration of cells should be $10 \times 10^{6}$ cells $/ \mathrm{ml}$.

13. At least $4 \mathrm{~h}$ after irradiation the bone marrow cells can be injected intravenously. Warm the irradiated mice under the heating lamp and inject each animal with $200 \mu \mathrm{l}$ of the bone marrow cells. Each mouse should receive $2 \times 10^{6}$ cells. Return the mice to their original cages and add enrofloxacin to the drinking water for 10 days. After 6-8 weeks, collect blood samples via tail nick to analyze the hematopoietic cell 
Table 3

Monoclonal antibodies to analyze innate cellular influx

\begin{tabular}{llll}
\hline Marker & Fluorochrome & Clone & Supplier \\
\hline Ly6C & FITC & AL-21 & BD Biosciences \\
\hline Ly6G & PE & lA8 & BD Biosciences \\
\hline CD1lc & PE-Texas Red & N418 & Invitrogen \\
\hline CD8a & PerCP-Cy5.5 & $53-6.7$ & BD Biosciences \\
\hline CD86 & PE-Cy7 & GL1 & BD Biosciences \\
\hline ratIgG2a & PE-Cy7 & eBR2a & eBioscience \\
\hline OVA & Alexa Fluor 647 & & Invitrogen \\
\hline MHC II & Alexa Fluor 700 & M5/114.15.2 & eBioscience \\
\hline F4/80 & APC-eFluor780 & BM8 & eBioscience \\
\hline CD11b & eFluor450 & M1/70 & eBioscience \\
\hline FcgRII/III & & $2.4 G 2$ & In house \\
\hline
\end{tabular}

chimerism of the mice. If the donor is carrying a GFP expression marker or unique cell surface markers, such as CD45.1 or CD 45.2, then the extent of chimerism can be analyzed by flow cytometry.

14. Allergic asthma experiments can be initiated 10-12 weeks after irradiation. This will allow the long-lived alveolar macrophages in the lung to be replenished by the newly derived bone marrow.

3.8 DAMP and

PAMPs as Adjuvants
1. Resuspend the PL or BAL cell pellet in 200-500 $\mu$ l of FACS buffer.

2. Count an aliquot of the samples using Trypan blue and a hemacytometer.

3. Transfer $1 \times 10^{6}$ cells to a FACS flexiplate $(\max 200 \mu \mathrm{l})$.

4. Centrifuge the plate for $3 \mathrm{~min}$ at $400 \times g$ and $4{ }^{\circ} \mathrm{C}$.

5 . Remove the supernatant and add $40-50 \mu$ of staining mix, which has been prepared with the monoclonal antibodies described in Table 3 in FACS buffer.

6. Incubate the supernatant for $30 \mathrm{~min}$ at $4{ }^{\circ} \mathrm{C}$ or $15 \mathrm{~min}$ at room temperature.

7. Add $150 \mu \mathrm{l}$ of FACS buffer.

8. Centrifuge the plate for $3 \mathrm{~min}$ at $400 \times \mathrm{g}$ and $4{ }^{\circ} \mathrm{C}$. 

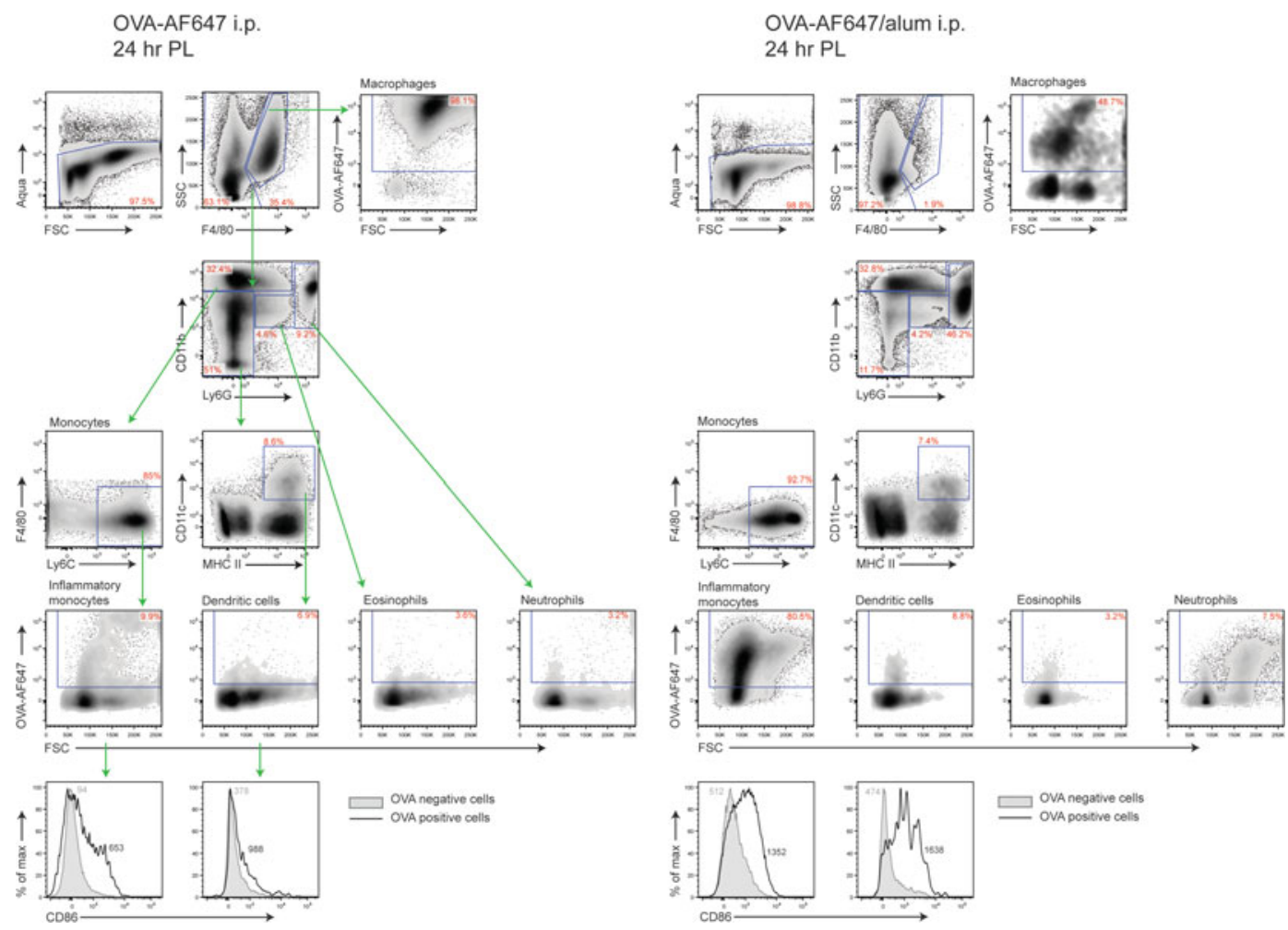

Fig. 3 Gating strategy with and without adjuvant in PL

9. Remove the supernatant and suspend the cell pellet in $200 \mu \mathrm{l}$ of FACS buffer. This step is to wash all of the free monoclonal antibodies from the pellet.

10. Centrifuge the plate for $3 \mathrm{~min}$ at $400 \times \mathrm{g}$ and $4{ }^{\circ} \mathrm{C}$.

11. Remove the supernatant and suspend the pellet in $200 \mu \mathrm{l}$ of FACS buffer. Transfer the cells to FACS tubes and evaluate using a flow cytometer.

12. Data analysis is done according to Fig. 3 ( see Note 13).

\subsection{Dendritic Cell} Migration
1. Dissect the lung and LNs and keep them in HBSS on ice.

2. Cut the tissue into small pieces in a $35 \mathrm{~mm}$ petri dish using the iris scissors.

3. Transfer the pieces into a $15 \mathrm{ml}$ tube and rinse the petri dish with digestion medium. For each lung half, use $500 \mu \mathrm{l}$ of medium and for LNs use $200 \mu \mathrm{l}$ per organ. Keep on ice until all of the samples are processed. 
Table 4

Monoclonal antibodies to track DC migration and identify DC subsets

\begin{tabular}{llll}
\hline Marker & Fluorochrome & Clone & Supplier \\
\hline BST-2 & FITC & 120G8 & Made in house \\
\hline MHC II & PE & M5/114.15.2 & BD Biosciences \\
\hline CD11c & PE-Texas Red & N418 & Invitrogen \\
\hline CD11b & PerCP-Cy5.5 & Ml/70 & eBioscience \\
\hline CD103 & Biotin & $2 \mathrm{E} 7$ & BD Biosciences \\
\hline Streptavidin & PE-Cy7 & & eBioscience \\
\hline OVA & Alexa Fluor 647 & & Invitrogen \\
\hline FcgRII/III & & $2.4 \mathrm{G} 2$ & In house \\
\hline
\end{tabular}

4. Place the tubes in the warm water bath two times for $15 \mathrm{~min}$ each. After each 15-min incubation, resuspend the suspension vigorously using a Pasteur pipet.

5. Filter the cell suspension over a $100 \mu \mathrm{m}$ cell strainer and transfer the samples into new $15 \mathrm{ml}$ tubes.

6. Centrifuge all samples at $4{ }^{\circ} \mathrm{C}$ at $400 \times g$ for $7 \mathrm{~min}$.

7. Resuspend the cell pellet in RBC-lysis buffer. Each LN should be resuspended in $200 \mu \mathrm{l}$ and each lung half should be resuspended in $1 \mathrm{ml}$. Leave the cell suspensions on ice for $4 \mathrm{~min}$ and shake occasionally.

8. Add excess volumes of FACS-buffer and centrifuge all of the samples at $4{ }^{\circ} \mathrm{C}$ at $400 \times g$ for $7 \mathrm{~min}$.

9. Resupend the cell pellet in FACS-buffer and count the number of cells in each sample using Trypan blue and a hemacytometer.

10. Proceed with FACS-staining as described in Subheading 3.8 using antibodies described in Table 4.

11. Before acquiring on the flow cytometer, samples should be filtered using a filter plate of tubes with a filter cap to prevent clogs during acquisition.

12. Data analysis is done according to Fig. 4 (see Note 13). 


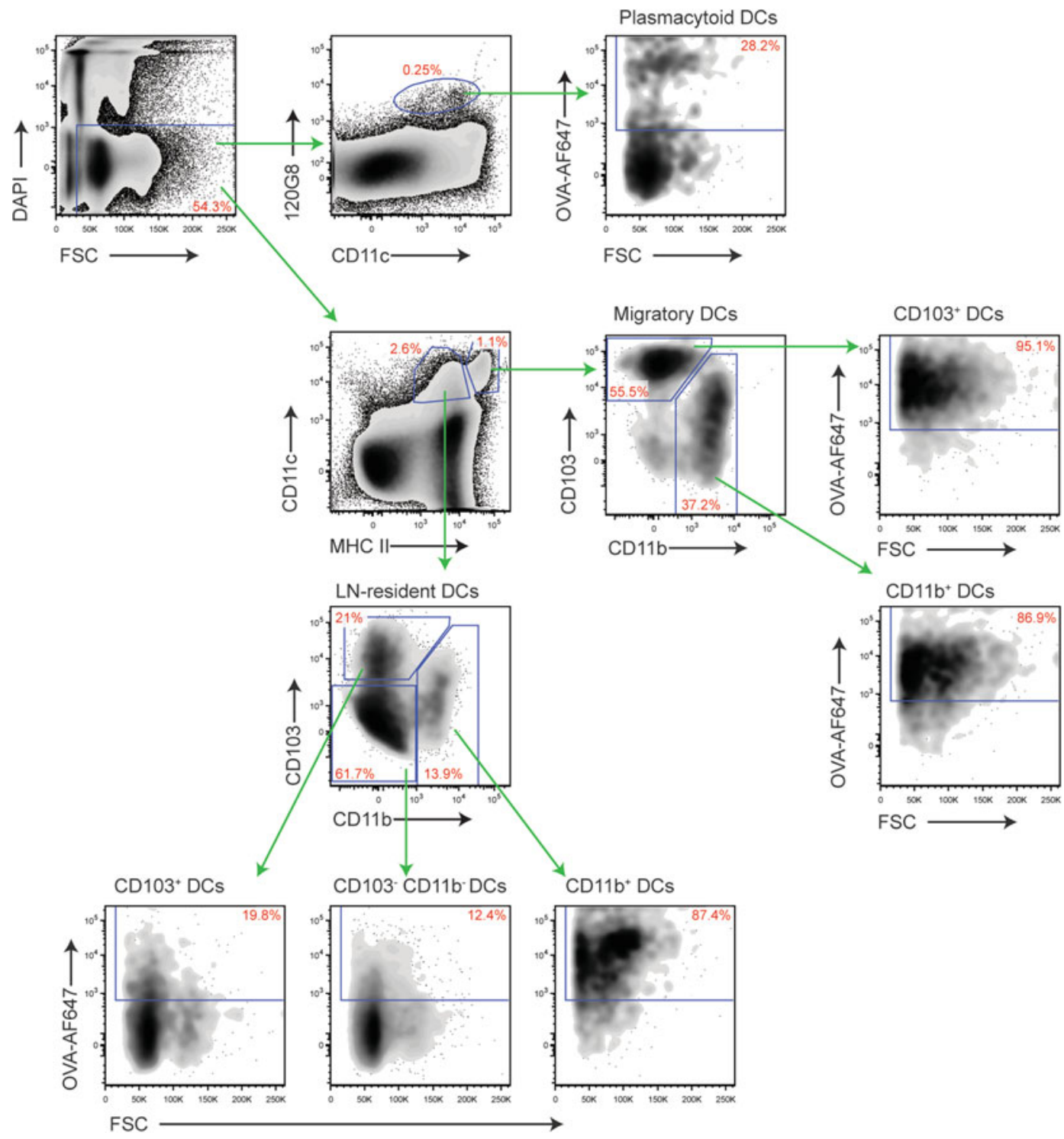

Fig. 4 Gating strategy for DC migration in mediastinal LNs

\section{Notes}

1. We would like to stress the importance of monitoring the health status of your animal facility. It is known that certain pathogens (containing PAMPs) will greatly influence the outcome of the measurements described throughout this protocol. As far as possible within your facility, housing specific pathogenfree (SPF) mice in individually ventilated cages (IVC) would be optimal. 
2. Make solutions no more than $24 \mathrm{~h}$ prior to use and mix well before use. Air bubbles will interfere with cutting and interpreting the morphology of lung sections.

3. The cold lysis buffer described here is for the extraction of extracellular and intracellular proteins and is therefore adequate for cytokines and other messengers. It will also extract many transmembrane proteins, but in this case, it is recommended to confirm the efficiency of the technique with your specific transmembrane protein. If ineffective, another lysis buffer can be used, making sure not to include any detergent in the homogenization phase. Omitting the detergent will avoid foaming of the solution.

4. The described lysis buffer contains sodium orthovanadate and sodium fluoride $(\mathrm{NaF})$ : these are phosphatase inhibitors. If you have no interest in protein phosphorylation (e.g., STAT proteins to assess activation of cytokine receptors), these reagents are dispensable in the buffer. Aprotinine and leupeptine are protease inhibitors and are necessary to avoid protein degradation.

5. If you do not want to analyze cytokines in the BAL, it is better to take the BAL with three times $1 \mathrm{ml}$ of PBS/EDTA (for a total of $3 \mathrm{ml}$ ).

6. Make sure that there are no contaminating cells in the supernatant as this will greatly influence your measurement. Cells are the source of the DAMPs.

7. Do not use injectable anesthetics via the peritoneal route, as they can negatively impact cell viability.

8. Make sure that the slides never run dry; this will influence the result of your staining.

9. Make sure to always take an extra section alone without a primary antibody, but stained with the secondary antibody to set the background on the confocal microscope. Lungs are full of autofluorescent cells.

10. Depending on the techniques applied to the homogenate, some components of the lysis buffer (e.g., Igepal as a detergent) might interfere with the assay. The first attempt should be to dilute the lysate, which should reduce the impact of the lysis buffer components. If this cannot be achieved, modifications of the lysis buffer can be envisaged for the specific protocol. However, for the procedures described here, using recommended dilutions, no interference is expected.

11. The dose of irradiation should be confirmed in each lab. This dose is general enough to deplete all bone marrow cells in $\mathrm{C} 57 \mathrm{Bl} / 6$ mice. However, mice on a BALB/c background are more sensitive to irradiation. Thus, it might be necessary to 
irradiate the mice twice with 4 Gy at a 4-h interval. The mice are then injected early the next morning with the new bone marrow.

12. Make sure that you have enough mice to make four groups with the following controls: WT into WT; KO into WT; WT into $\mathrm{KO}$; and $\mathrm{KO}$ into $\mathrm{KO}$. Irradiation induces changes to the immunological response of mice, which must be controlled for in the experiment. Take cells for compensation. This means that all fluorochromes used in the mix are prepared as a single stain.

13. Take cells for fluorescence minus one (FMO) control staining to optimize your gating strategy [22]. FMO samples contain all fluorochromes except one. When placing your gate on the staining of the fluorochrome missing in the FMO, the background fluorescence is observed. By using FMO samples, you ensure that your gates are placed on positive cells and not on background fluorescence induced by other fluorochromes.

\section{References}

1. Lambrecht BN, Hammad H (2010) The role of dendritic and epithelial cells as master regulators of allergic airway inflammation. Lancet 376(9743):835-843

2. Banchereau J, Steinman RM (1998) Dendritic cells and the control of immunity. Nature 392:245-252

3. Hammad H, Lambrecht BN (2011) Dendritic cells and airway epithelial cells at the interface between innate and adaptive immune responses. Allergy 66(5):579-587

4. Willart M, Hammad H (2011) Lung dendritic cell-epithelial cell crosstalk in Th2 responses to allergens. Curr Opin Immunol 23(6):772-777

5. Eisenbarth SC, Piggott DA, Huleatt JW, Visintin I, Herrick CA, Bottomly K (2002) Lipopolysaccharide-enhanced, toll-like receptor 4 -dependent $\mathrm{T}$ helper cell type 2 responses to inhaled antigen. J Exp Med 196(12): 1645-1651

6. Tan AM, Chen HC, Pochard P, Eisenbarth SC, Herrick CA, Bottomly HK (2010) TLR4 signaling in stromal cells is critical for the initiation of allergic Th2 responses to inhaled antigen. J Immunol 184(7):3535-3544

7. Qu Y, Micaghi S, Newton K, Gilmour LL, Louie S, Cupp JE, Dubyak GR, Hackos D, Dixit VM (2011) Pannexin-l is required for ATP release during apoptosis but not for inflammasome activation. J Immunol 186(11): 6553-6561

8. McDermott MF, Tschopp J (2007) From inflammasomes to fevers, crystals and hypertension: how basic research explains inflam- matory diseases. Trends Mol Med 13(9): 381-388

9. Dinarello CA (2011) Interleukin-1 in the pathogenesis and treatment of inflammatory diseases. Blood 117(14):3720-3732

10. Hornung V, Bauernfeind F, Halle A, Samstad EO, Kono H, Rock KL, Fitzgerald KA, Latz E (2008) Silica crystals and aluminum salts activate the NALP3 inflammasome through phagosomal destabilization. Nat Immunol 9(8): $847-856$

11. Martinon F, Petrilli V, Mayor A, Tardivel A, Tschopp J (2006) Gout-associated uric acid crystals activate the NALP3 inflammasome. Nature 440(7081):237-241

12. Kool M, Willart MA, van Nimwegen $M$, Bergen I, Pouliot P, Virchow JC, Rogers N, Osorio F, Reis E, Sousa C, Hammad H, Lambrecht BN (2011) An unexpected role for uric acid as an inducer of T helper 2 cell immunity to inhaled antigens and inflammatory mediator of allergic asthma. Immunity 34(4):527-540

13. Lambrecht BN, Kool M, Willart MA, Hammad H (2009) Mechanism of action of clinically approved adjuvants. Curr Opin Immunol 21(1): 23-29

14. Kawai T, Akira S (2011) Toll-like receptors and their crosstalk with other innate receptors in infection and immunity. Immunity $34(5)$ : 637-650

15. Barton GM, Kagan JC (2009) A cell biological view of Toll-like receptor function: regulation through compartmentalization. Nat Rev Immunol 9(8):535-542 
16. Kono H, Karmarker D, Iwakura Y, Rock KL (2010) Identification of the cellular sensor that stimulates the inflammatory response to sterile cell death. J Immunol 184(8): $4470-4478$

17. Scaffidi P, Misteli T, Bianchi ME (2002) Release of chromatin protein HMGBl by necrotic cells triggers inflammation. Nature 418(6894):191-195

18. Idzko $M$, Hammad $H$, van Nimwegen $M$, Kool M, Willart MA, Muskens F, Hoogsteden HC, Luttmann W, Ferrari D, Di Virgilio F, Virchow JC Jr, Lambrecht BN (2007) Extracellular ATP triggers and maintains asthmatic airway inflammation by activating dendritic cells. Nat Med 13(8): 913-919
19. Kool M, Soullie T, van Nimwegen M, Willart MA, Muskens F, Jung S, Hoogsteden HC, Hammad H (2008) Alum adjuvant boosts adaptive immunity by inducing uric acid and activating inflammatory dendritic cells. J Exp Med 205(4):869-882

20. Martinon F (2008) Detection of immune danger signals by NALP3. J Leukoc Biol 83(3):507-511

21. Petrilli V, Dostert C, Muruve DA, Tschopp J (2007) The inflammasome: a danger sensing complex triggering innate immunity. Curr Opin Immunol 19(6):615-622

22. Roederer M (2002) Compensation in flow cytometry. Curr Prot Cytometry/editorial board, J. Paul Robinson, managing editor. Chapter 1: Unit 114 